\title{
Intensity / Distance Profile Raman Microprobe Spectroscopy to Study Adsorption and Orientation of Species In Metal/Solution Boundary Region.
}

\author{
Toru OZEKI*， and Donald E. IRISH
}

\begin{abstract}
Received April 25, 2002
Dependence of adsorption and orientation of species in metal / solution boundary region upon the applied potential as well as the solution $\mathrm{pH}$ was investigated for quinoline / mercury system by using the intensity / distance profile Raman microprobe spectroscopy. Generally, the Raman peak intensity - distance profile is that the real concentration - distance profile is convoluted by a window function determined by the focal depth of the objective lens. The treatment of the deconvolution to reproduce real concentration / distance profile was developed. The distance profile of adsorption and orientation in the boundary region was estimated with the precision of several $\mu \mathrm{m}$. Quinoline molecules existing in alkaline solutions were adsorbed on the mercury surface in three orientations: a perpendicular orientation from -1.1 to $-0.5 \mathrm{~V}$, a flat orientation -0.3 to $-0.1 \mathrm{~V}$, and a mixture of them from -0.5 to $-0.3 \mathrm{~V}$. In acidic solutions, quinolinium ions were adsorbed on the mercury surface in different three orientations: a perpendicular orientation with $\mathrm{NH}^{+}$site directed toward mercury surface from -0.6 to $-0.4 \mathrm{~V}$, the opposite perpendicular orientation with $\mathrm{NH}^{+}$site toward bulk solution from +0.2 to $+0.4 \mathrm{~V}$ through random orientations from -0.4 to $+0.2 \mathrm{~V}$. The thickness of the adsorption layer of quinoline and that of quinolinium ion were estimated.
\end{abstract}

\section{INTRODUCTION}

Knowledge of the concentration - distance profile in a boundary region such as diffusion layer between the electrode surface and the bulk of solution is important to study electrochemical reaction mechanisms. Properties of boundary region are significantly different from those of the bulk. For example, many organic species adsorb on the electrode surface with several kinds of orientation. Concentration and direction of orientation depend upon the applied potential and solution properties such as $\mathrm{pH}$. Multilayer adsorption occurs in several systems. Thus the measurement of structure and physical properties of metal / solution boundary region

兵庫教育大学自然系化学教室（T673-1494 兵 庫県加東郡社町下久米 942-1) Hyogo University of Teacher Education ( Shimokume 942-1, Yashiro-cho, Kato-gun, Hyogo 673-1494, Japan)

* Department of Chemistry, University of Waterloo (Waterloo, ON Canada N2L 3G1) keywords: Raman microprobe spectroscopy; quinoline; mercury; adsorption; orientation; intensity / distance profile. is required. The investigation of such a boundary region is the subject of many researchers and new tools have been complemented to the traditional techniques ${ }^{1-9}$ ). Among them is Raman microprobe spectroscopy ${ }^{10,11)}$, in which the laser beam is irradiated into a very tiny region inside the solution through an objective lens, and scattered light is collected again by the same lens. The collected information comes from the very tiny region of several tens $\mu \mathrm{m}$ determined by the focal depth of the objective lens.

Generally speaking, the thickness of the adsorption layer is nanometer order but that of the diffusion layer is several tens $\mu \mathrm{m}$. Thus the concentration / distance profile in the boundary region can be studied by using the Raman microprobe spectroscopy. Based on this idea, a new technique -- intensity / distance profile Raman microprobe spectroscopy -- was developed by our group ${ }^{12-14)}$.

However, the measured Raman peak intensity is that the real concentration - distance 
profile is convoluted by a window function determined by the focal depth of the objective lens. Thus the treatment of the deconvolution to reproduce the real concentration / distance profile was developed. This method has been applied to several electrochemical systems including a ferrocyanide / ferricyanide redox system $^{12)}$, and a study of photo-induced crystallization of triethylenediamine triiodide upon a silver electrode ${ }^{13,14)}$.

In this paper, the principle and procedure of this technique are demonstrated. As an example, a study of adsorption of quinoline on mercury electrode is reported. Quinoline molecules were adsorbed upon the mercury surface by different orientations depending upon the applied potential ${ }^{15,16)}$. The thickness of the adsorption layer was estimated under different experimental conditions.

\section{EXPERIMENTAL SECTION}

\subsection{Chemicals}

Quinoline available from the Aldrich Chemical Company was used without further purification. Mercury was purity $99.9998 \%$ from the Johnson Matthey Co. Milli-Q water was used to prepare samples solutions. Other chemicals were all analytical grade reagents. Sodium perchlorate was used as a supporting salt as well as an internal standard of Raman peak intensity inside solution.

Two solutions, (a) $20 \mathrm{mM}$ quinoline, $0.1 \mathrm{M}$ $\mathrm{NaClO}_{4}, 0.1 \mathrm{M} \mathrm{NaOH}$, and (b) $40 \mathrm{mM}$ quinoline, $0.1 \mathrm{M} \mathrm{HClO}_{4}$, was used. The acid dissociation constant ( $\mathrm{pKa}$ ) of quinoline is about $4.94{ }^{17}$ ). Thus, quinoline exists as a non-charged molecule in the solution (a), but as a quinolinium ion in the solution (b).

\subsection{Spectroelectrochemical cell}

A schematic illustration of the electrochemical / Raman cell is shown in Fig.1. The cell (E) was fabricated from acryl resin of $50 \mathrm{~mm}$ diameter. The cell had an optical window (C) for which an anhydrous quartz of $30 \mathrm{~mm}$ diameter and $2 \mathrm{~mm}$ thickness was used. This window was removable for a new drop of mercury to be set into the cell. Inside the cell, two lead wires (D) and (F) were introduced and a reference electrode $(G)$ was connected. The (F) was a Pt wire of $1 \mathrm{~mm}$ diameter introduced to the central dent of the cell where a drop of mercury was put. In this experiment a 0.85 0.87 g mercury drop was used. The diameter of this mercury drop was about $5 \mathrm{~mm}$. The (D) was a Pt wire of $1 \mathrm{~mm}$ diameter used as a counter electrode. The reference electrode was a $\mathrm{Ag} / \mathrm{AgCl} / 1 \mathrm{M} \mathrm{KCl}$, and a $5 \%$ agar salt bridge of $0.5 \mathrm{M}$ sodium sulfate was used to prevent the precipitation of $\mathrm{KClO}_{4}$. The sample solution was introduced from an inlet (H) at the left hand side of the cell after dissolved oxygen was removed by flowing high purity $\mathrm{N}_{2}$ gas ${ }^{15}$. The volume of the solution filled inside the cell was about $3 \mathrm{~cm}^{3}$.

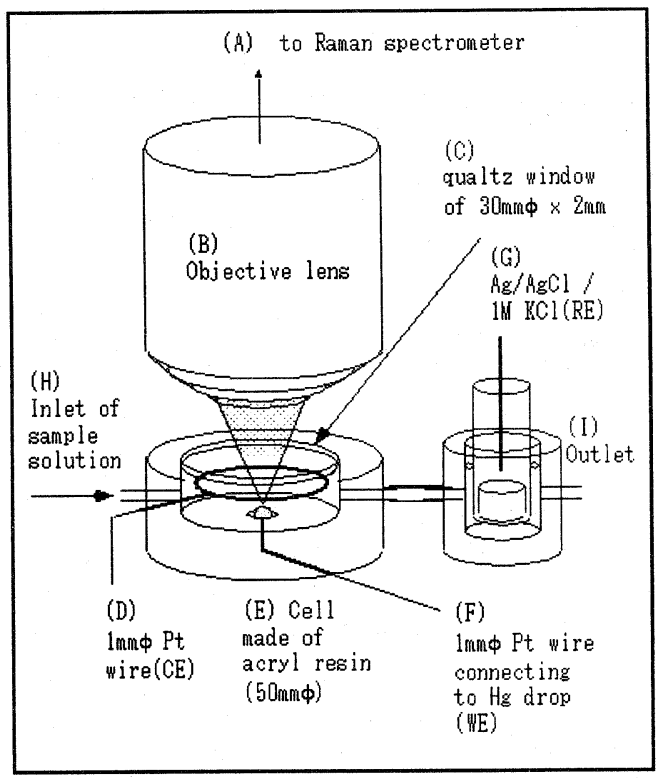

Fig.1 Schematic illustration of the cell.

\subsection{Electrochemical measurement}

Cyclicvoltammograms were measured with an EG\&G PAR Model 273 potentio / galvanostat interfaced to a PC. Another laboratory - made potentiostat was used to apply a controlled potential to the cell during Raman measurement. The potential of the reference electrode was $-0.003 \mathrm{~V}$ against SCE (the theoretical value is $-0.016 \mathrm{~V}$ ).

\subsection{Raman microprobe measurement}

A Renishaw 1000 Raman Imaging 
Microscope system was used. The instrument consists of an Olympus microscope system, where a control device of a $x-y-z$ movable stage operated by a computer is assembled. An excitation laser beam was a $632.8 \mathrm{~nm}$ beam from a Melles Griot $35 \mathrm{~mW} \mathrm{He}-\mathrm{Ne}$ laser. The Raman system irradiates the laser beam at a focal point through an long working-length objective lens ((B) of Fig.1); the same objective lens collects the scattered light. In this experiment, an objective lens IC50 (with objective magnification of 50 times) was used. The spatial resolving power of this objective lens was characterized by using a silicon crystal of surface flatness of $1 \mu \mathrm{m}$ order ${ }^{12,13)}$. The intensity of $520 \mathrm{~cm}^{-1}$ peak ascribed to the silicon crystal was measured while the focal point was changed from just above the surface of the crystal to upward or to downward. As seen in Fig.2, the peak intensity was the highest when the focal point was adjusted just upon the surface. When the focal point was moved upward or downward, the peak intensity decreased steeply. The dependence of the peak intensity upon the distance from the surface was characterized by the following Lorenz type function:

$$
I(h)=\frac{A}{1+B h^{2}}
$$

where $\mathrm{A}$ and $\mathrm{B}$ are fitting parameters. The width at the half-height $(2 / \sqrt{B})$ was determined as $25.7 \mu \mathrm{m}$. It means that the scattered light is collected at about $25.7 \mu \mathrm{m}$ region around the focal point.

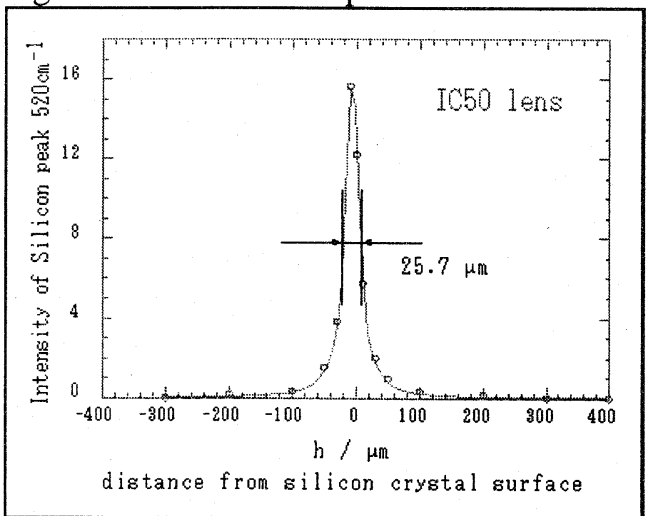

Fig.2 Focal depth profile of the objective lens IC50.

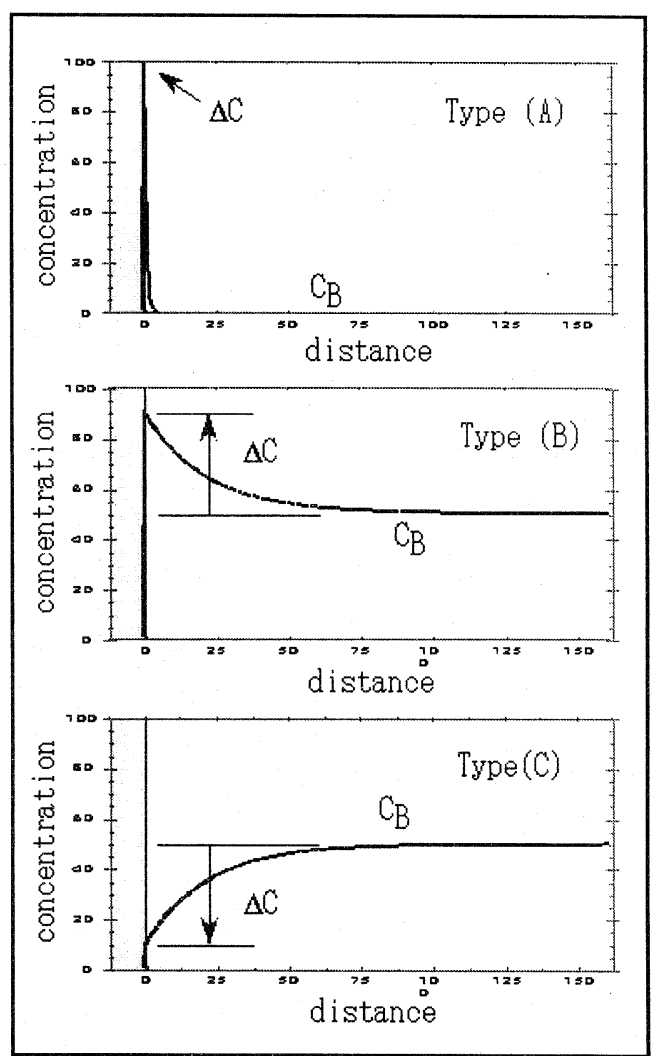

Fig.3 Schematic illustrations of typical concentration - distance profiles.

\section{RAMAN PEAK INTENSITY AND DECONVOLUTION}

\subsection{Typical examples of concentration - distance profile}

When no current flows and no specific adsorption occurs, the concentration of species is constant from the bulk of the solution to the electrode surface. However, in real electrochemical system, current flows and the specific adsorption occurs. The typical concentration - distance profile of the specific adsorption is illustrated in Fig.3-(A). In this case, it is assumed that the bulk concentration is very low. Fig.3-(B) and Fig.3-(C) show the cases that the concentration of the species at the electrode surface is higher or lower than that of the bulk solution by redox reactions. A typical example ascribed to these cases (Fig.3-(B) and (C)) was ferrocyanide / ferricyanide redox system $^{12,13)}$. The adsorption of the iodide of 
diprotonated

triethylendiamine

$\left(\mathrm{DABCO}-\mathrm{H}_{2}{ }^{2+}\right.$ ) upon the silver electrode at negative potential is explained by a combination of Fig.3-(A) and Fig.3-(B). The crystal growth of DABCO- $\mathrm{H}_{2}{ }^{2+}-\left(\mathrm{I}_{3}{ }^{-}\right)_{2}$ at positive potential from the site of laser illumination has been studied by the intensity / distance profile Raman microprobe spectroscopy ${ }^{14,18)}$.

\subsection{Raman peak intensity and convolution}

As mentioned above, the focal depth profile of the objective lens can be described by Eq.1. The spatial resolving power of the IC50 lens was about $25.7 \mu \mathrm{m}$. Here, suppose that a kind of molecule adsorbs just upon the electrode surface and its bulk concentration is zero as seen in Fig.3-(A). The Raman peak intensity observed in this system through the objective lens is described by the following convolution:

$$
I(h)=\int_{-\infty}^{+\infty} \mu C(h-x) W(x) d x
$$

where $\mu$ is the molar Raman scattering coefficient, $I(h)$ is the Raman peak intensity measured at the distance $h$ from the surface, $C(h)$ is the true concentration of the species at the distance $h$, and the $W(x)$ is the window function describing the focal depth of the objective lens used.

In this case, the window function $W(x)$ is expressed by the Eq.1 obtained from the flat silicon crystal. Then the measured intensity $I(h)$ is obtained by the convolution (Eq.2) of the concentration - distance profile $C(h)$ with the window function $W(x)$. By the way, in the case of Fig.3-(A) :

$$
\begin{array}{ll}
C(h)=C_{0} & (h=0) \\
C(h)=0 & (h ? 0)
\end{array}
$$

where $C_{0}$ is the constant describing the density of the adsorbed species at the electrode surface. Then Eq. 2 becomes:

$$
I(h)=C_{0} W(h)
$$

Namely, the obtained intensity - distance profile is the $C_{0}$ times the window function $W(h)$ shown in Fig.2.

\subsection{Deconvolution procedure}

Here a deconvolution treatment was introduced in order to reproduce the true concentration - distance profile from the observed intensity - distance profile. There are several algorithms to carry out deconvolution ${ }^{19-21)}$. One of them, an iterative simulation method, was used in the previous study ${ }^{13,14)}$. However, this method requires the data of small variance. The quinoline mercury system has given relatively large measurement variance as shown later. Thus the concentration - distance profile was reproduced by assuming the following concentration - distance function, as shown in Fig.3-(B) and Fig.3- (C).

$$
C(h)=C_{B}+\Delta C e^{-\left(\log (2)^{*} h / d\right)}
$$

where $C_{B}$ is the bulk concentration of the species and $\Delta C$ is the excess concentration on the surface as compared with the bulk concentration $\left(\Delta C=C(0)-C_{B}\right)$. And the $d$ is the thickness of the adsorption layer defined as the "half distance" where $\left(C(d)-C_{B}\right)$ becomes $\triangle C / 2$.

By using $\Delta C$ and $d$ as fitting parameters, the following error function was defined :

$$
\begin{aligned}
& E(\Delta C, d)= \\
& \quad \int_{-\infty}^{+\infty}\left\{I(h)-\int_{-\infty}^{+\infty} \mu C(h-x) W(x) d x\right\}^{2} d h
\end{aligned}
$$

By using the variable-size simplex algorithm ${ }^{22)}$, a set of parameters $(\Delta C, d)$ giving the minimum value of the $E(\Delta C, d)$ was optimized.

\section{RESULTS AND DISCUSSION}

As an application of "intensity / distance profile Raman microprobe spectroscopy", adsorption and orientation of quinoline in the mercury / solution boundary region was investigated. A part of the experimental results and discussion has been reported elsewhere ${ }^{15,16)}$. The deconvolution analysis to reproduce the real concentration / distance profile was recently carried out, and its results are reported in this paper.

\subsection{Electrochemical properties of quinoline / mercury system}

The adsorption of quinoline upon the mercury surface has been studied by various techniques, including differential capacity ${ }^{23)}$, 
phase-sensitive ac voltammetry ${ }^{24)}$, ellipsometry 25), the electrocapillary method ${ }^{26,27)}$, potential step methods ${ }^{28)}$, and in situ FTIR spectroscopy ${ }^{29)}$. According to these reports, quinoline is adsorbed on the mercury surface with different potential-dependent orientations.

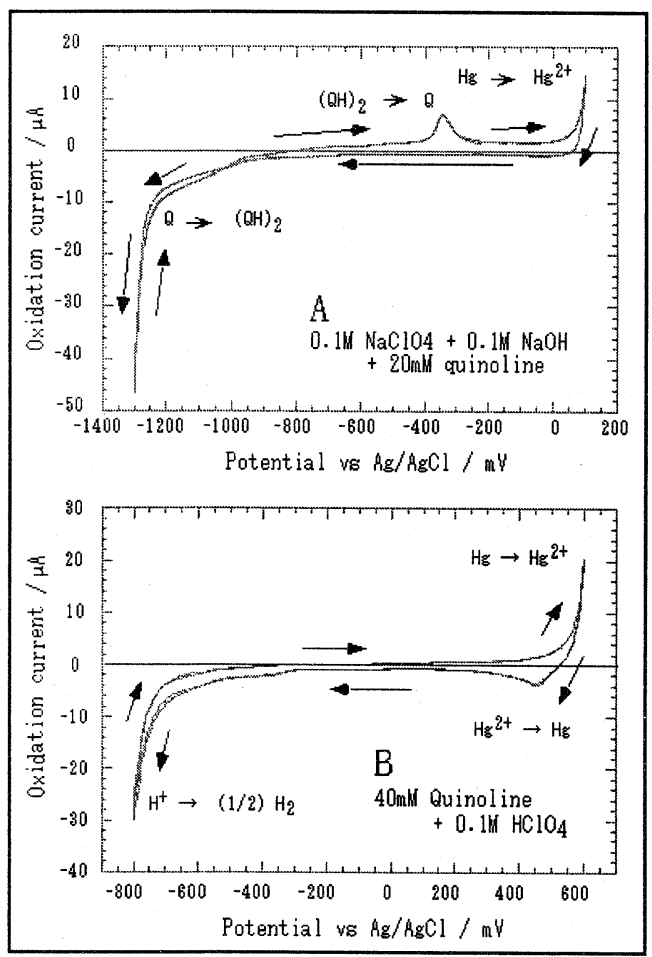

Fig.4 Cyclicvotammograms of A: $20 \mathrm{mM}$ quinoline, $0.1 \mathrm{M} \mathrm{NaClO}_{4}, 0.1 \mathrm{M} \mathrm{NaOH}$ solution, and B: $40 \mathrm{mM}$ quinoline, $0.1 \mathrm{M} \mathrm{HClO}_{4}$ solution.

In Fig.4-(A), a cyclic voltammogram of a $20 \mathrm{mM}$ quinoline, $0.1 \mathrm{M} \mathrm{NaClO}, 0.1 \mathrm{M} \mathrm{NaOH}$ solution (A) is shown. In the presence of quinoline, the reduction current of mercury ion, the reaction product of the oxidation step, was not observed, although it was observed in the absence of quinoline ${ }^{15)}$. Electrochemical behavior of quinoline has been studied by several authors ${ }^{30-33)}$. From Fig.4-(A), it is concluded that the adsorbed quinoline blocks some electrochemical reactions by covering the mercury electrode probably at two potential regions; one is from -1.1 to $-0.5 \mathrm{~V}$, and the other is from -0.3 to $+0.1 \mathrm{~V}$. A measurement of the point of zero charge (pzc) using a dropping mercury electrode has shown a very drastic change in dropping time at $-0.55 \mathrm{~V}$ so that the adsorption of quinoline seems to lower the surface tension of the mercury / solution interface $^{15,25}$.

However, a cyclic voltammogram of the $40 \mathrm{mM}$ quinoline, $0.1 \mathrm{M} \mathrm{HClO}_{4}$ solution shown in Fig.4-(B) is almost same as that obtained for the solution without quinoline ${ }^{16)}$. It means that no blocking by the quinolinium ion was observed in the acidic solution. A measurement of the pzc also has shown that the presence of quinolinium ion does not give any marked change of the dropping time ${ }^{16)}$.

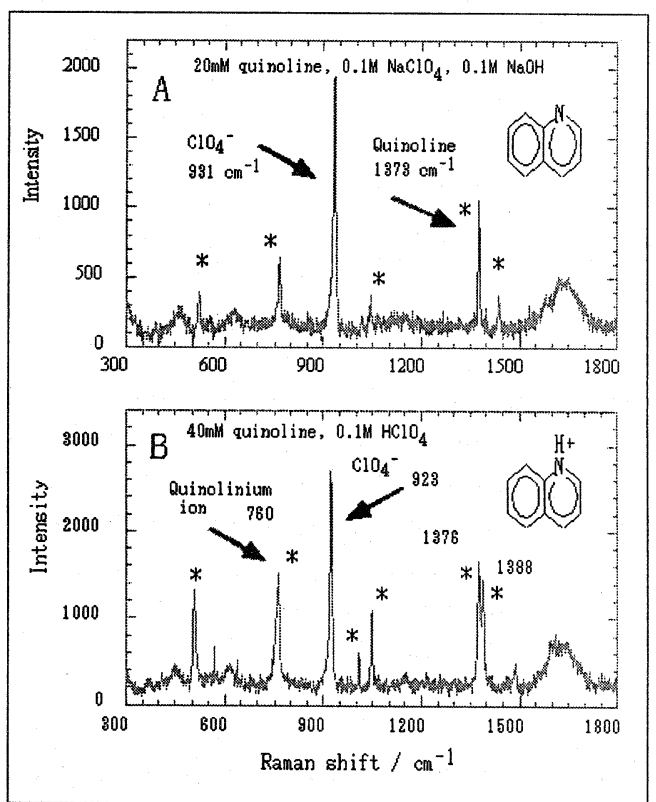

Fig.5 Bulk Raman spectra of (A) $20 \mathrm{mM}$ quinoline, $0.1 \mathrm{M} \mathrm{NaClO}_{4}, 0.1 \mathrm{M} \mathrm{NaOH}$ solution and (B) $40 \mathrm{mM}$ quinoline, $0.1 \mathrm{M} \mathrm{HClO}_{4}$ solution. The peaks marked by *are those of quinoline.

\subsection{Bulk Raman spectrum and surface Raman spectrum of quinoline}

According to the published reports, the quinoline molecule is adsorbed on the mercury surface with several orientations 24,26,34). When the adsorbed species interacts with the electrode metal, particular change of Raman spectrum is expected. One of such effects is the SERS (surface enhanced Raman scattering). Features of SERS are: (1) large enhancement of 
the intensity of the Raman peak ascribed to the adsorbate as compared with that of the bulk species, (2) prominence of the enhancement for certain vibration modes, (3) its dependence upon the angle of incidence of the laser. A large number of molecules and ions showing SERS effects have been reported for the metals such as silver, gold, copper and so on ${ }^{35-37)}$. However, few report on the SERS effect has been reported for mercury.

In Fig.5-(A) and (B), the bulk Raman spectra of quinoline are shown for the $20 \mathrm{mM}$ quinoline, $0.1 \mathrm{M} \mathrm{NaClO}_{4}, 0.1 \mathrm{M} \mathrm{NaOH}$ solution, and for the $40 \mathrm{mM}$ quinoline, $0.1 \mathrm{M} \mathrm{HClO}_{4}$ solution. The peaks marked by a symbol * are those ascribed to quinoline. The other peaks are ascribed to perchlorate ion. A peak observed at $1373 \mathrm{~cm}^{-1}$ of Fig.5-(A) is very intense, but is split into two peaks 1376 and $1388 \mathrm{~cm}^{-1}$ in Fig.5-(B). Rather a peak intensity observed at $760 \mathrm{~cm}^{-1}$ is intense and single.

Surface Raman spectra were also measured while the focal point of the microprobe was adjusted just upon the mercury surface. But the observed peak positions of the surface Raman spectra were almost the same as those of the bulk Raman spectra although the peak intensities of the surface Raman spectra were a little potential -dependent as mentioned below. We have concluded that no SERS effect is observed for quinoline - mercury system ${ }^{15,16)}$.

\subsection{Potential dependence of Raman peak intensity of quinoline / mercury system}

No difference was observed between the peak positions of quinoline of the surface Raman spectra and those of the bulk Raman spectra. But, peak intensities of quinoline in the surface Raman spectra vary with the applied potential. Here relative peak intensity of the $1373 \mathrm{~cm}^{-1}$ peak of quinoline $\left(\mathrm{I}_{1373}\right)$ to that at the $930 \mathrm{~cm}^{-1}$ peak of perchlorate ion $\left(\mathrm{I}_{930}\right)$ used as an internal standard was examined for the alkaline solution.

$$
\mathrm{R}=\frac{\mu_{Q}[Q]}{\mu_{\mathrm{ClO} 4}\left[\mathrm{ClO}_{4}^{-}\right]}=\frac{I_{1373}}{I_{930}}
$$

where $\mu_{\mathrm{Q}}$ and $\mu_{\mathrm{ClO} 4}$ are the molar Raman scattering coefficients of quinoline and perchlorate ion, respectively. In the acidic solution, an intensity of the $760 \mathrm{~cm}^{-1}$ peak of quinolinium ion was used in place of the 1373 $\mathrm{cm}^{-1}$ peak.

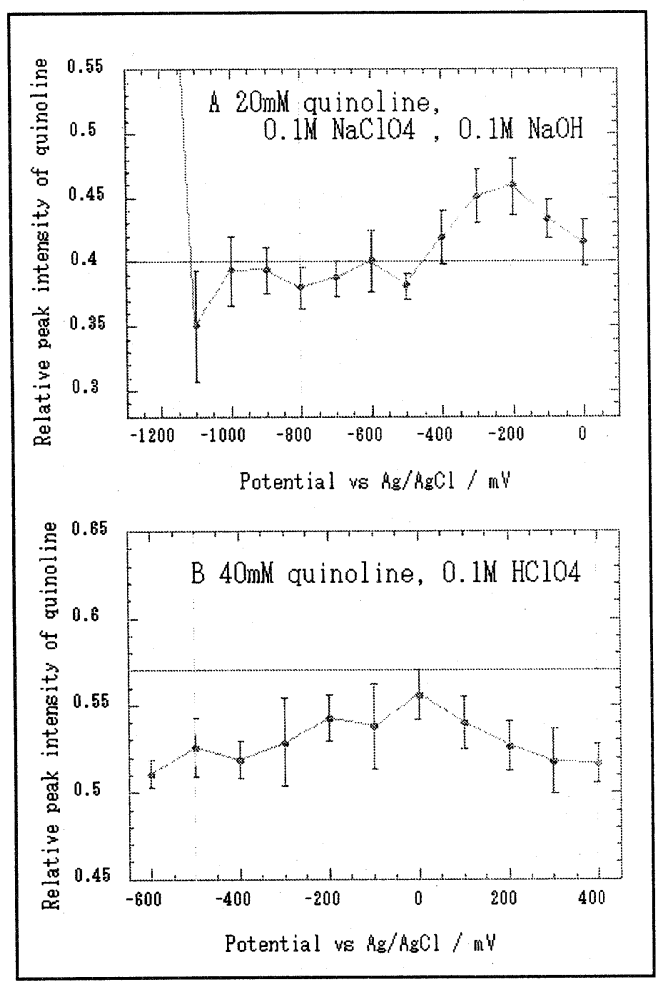

Fig.6 Dependence of relative peak intensity $R$ of quinoline upon the applied potential for (A) $20 \mathrm{mM}$ quinoline, $0.1 \mathrm{M} \mathrm{NaClO} 4,0.1 \mathrm{M} \mathrm{NaOH}$ solution and (B) $40 \mathrm{mM}$ quinoline, $0.1 \mathrm{M} \mathrm{HClO}_{4}$ solution. The horizontal lines indicate the $\mathrm{R}$ values observed in the bulk solution.

Fig.6-(A) shows the dependence of the relative peak intensity $R$ upon the applied potential measured for $20 \mathrm{mM}$ quinoline, $0.1 \mathrm{M}$ $\mathrm{NaClO}_{4}, 0.1 \mathrm{M} \mathrm{NaOH}$. A horizontal line at 0.4 of the relative peak intensity denotes the $R$ value in the bulk solution. Up to $-1 \mathrm{~V}$, change of the relative peak intensity was small, but at more negative potential the relative peak intensity increased steeply. When the potential was made more negative than $-1.1 \mathrm{~V}$, condensation of oily substance upon the mercury surface was observed; and a couple of min later, an oily substance covered almost all 
of the mercury surface ${ }^{15}$ ).

On the other hand, a closed look of Fig.6-(A) tells us that there is a maximum region of the relative peak intensity $R$ of quinoline around -0.3 to $-0.1 \mathrm{~V}$, and the value decreases in a region from -0.5 to $-1.1 \mathrm{~V}$. To check the reproducibility, at each condition at least four (typically five to six) measurements were carried out. The points are the averages of the measured $\mathrm{R}$ values; and the error-bars correspond to their standard deviations ${ }^{15)}$. The potential dependence of the intensities of the FTIR bands of the adsorbed isoquinoline upon the mercury surface has been reported by Blackwood and Pons ${ }^{29)}$. They have reported the same trend as that observed in this study.

The dependence of the relative peak intensity $\mathrm{R}$ of the quinolinium ion $\left(760 \mathrm{~cm}^{-1}\right)$ to the perchlorate ion $\left(928 \mathrm{~cm}^{-1}\right)$ upon the applied potential for the $40 \mathrm{mM}$ quinoline, $0.1 \mathrm{M} \mathrm{HClO}_{4}$ solution is shown in Fig.6-(B). A maximum appears between -0.4 and $+0.2 \mathrm{~V}$. A horizontal line drawn at 0.57 corresponds to the $\mathrm{R}$ value in the bulk solution ${ }^{16)}$.

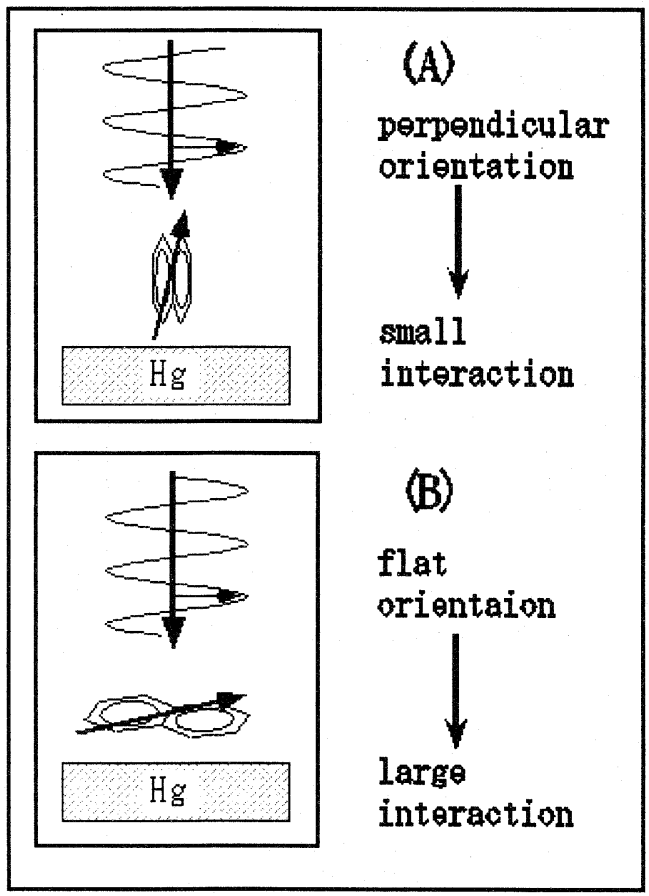

Fig.7 Schematic illustration of interactions of laser beam and quinoline.

\subsection{Interaction of laser beam and adsorbed quinoline}

Here, the relationship between the peak intensity of quinoline and its orientation was examined. The concentration of perchlorate ion used as an internal standard is constant at any place of the solution because this ion does not participate in electrochemical reaction. Thus, the change of the relative peak intensity $\mathrm{R}$ is ascribed to the change of concentration or the change of orientation of quinoline in the mercury / solution boundary region.

As mentioned in the section 4.1 , at the negative potential more than $-0.5 \mathrm{~V}$ in the alkaline solution, the change of the surface tension of the mercury / solution interface caused the drastic change of dropping time of a dropping mercury electrode. Namely, condensation (increase of the density) of quinoline molecules was observed. But the relative peak intensity $R$ decreased at that potential $(-0.5 \mathrm{~V})$ as compared with that at $-0.2 \mathrm{~V}$ as seen in Fig. 6-(A). Thus the decrease of $\mathrm{R}$ does not mean the decrease of the concentration of quinoline at the mercury surface; rather the orientation of the adsorbed quinoline molecules determines the peak intensity.

On the other hand, vibrational spectra of quinoline have been assigned by Wait and McNerney ${ }^{38)}$, and diagrams of their corresponding skeletal modes (for naphthalene) can be seen in a paper of Lippincott and O'Reilly ${ }^{39)}$. Many of the Raman peaks of quinoline are ascribed to the in-plane mode vibrations. The $1373 \mathrm{~cm}^{-1}$ peak is the strongest of the peaks of quinoline assigned to the $\mathrm{A}^{\prime}$ type gamma $\mathrm{C}-\mathrm{C}$ stretching vibration; the $760 \mathrm{~cm}^{-1}$ peak of the quinolinium ion is also ascribed to the $A^{\prime}$ type (in plane) skeletal distortion.

Interaction between the electromagnetic field of laser beam and polarizablity of quinoline is the major factor determining the intensity of Raman scattering. In this experiment, laser beam is directed exactly perpendicular to the mercury surface as shown in Fig.7. Then, strong interaction of the electromagnetic field of laser beam with the 
ring of the quinoline molecule is expected if the molecules are adsorbed on mercury with flat orientation as shown in Fig.7-(B); but very weak interaction is expected if the molecules are adsorbed with perpendicular orientation as shown in Fig.7-(A).

\subsection{Adsorption model of quinoline molecules on mercury surface}

Adsorption models of quinoline in the alkaline solution and those of quinolinium ion in the acidic solution are shown in Fig.8. In the previous study, the charge distribution in a quinoline molecule and in a quinolinium ion were calculated using MOPAC 16,40). The calculated directions of dipole are shown in the left panels of Fig. 8. Three types of orientation were proposed by our study for quinoline molecule adsorbed on the mercury electrode: (A) perpendicular from -1.1 to $-0.5 \mathrm{~V}$, (B) random from -0.5 to $-0.3 \mathrm{~V}$, and (C) flat from -0.3 to $-0.1 \mathrm{~V}$, depending upon the applied potential ${ }^{15)}$.

As mentioned in the section 4.4, strong interaction between the electromagnetic field of laser beam with the quinoline molecules is expected for those adsorbed with flat orientation; but very weak interaction is expected for the molecules adsorbed with perpendicular orientation. Thus, the orientation models shown in Fig.8-(A), (B) and (C) explain the dependence of the relative peak intensity $R$ and electrochemical properties of the quinoline molecule upon the applied potential.

Interaction between electric field across the electrode surface and dipole moment of quinoline seem to be the major factor causing the perpendicular orientation. Hydrophobic and hydrophilic interactions are also promoting the perpendicular orientation, with the hydrophobic carbon ring facing the mercury surface and the hydrophilic $\mathrm{N}$-group directed toward the solution ${ }^{25,26,29)}$. On the other hand, the force causing the flat orientation is the interaction between $\pi$ electrons of quinoline ring and mercury surface.

Both of perpendicular and flat orientations seem very dense. Thus the electron transfer across such a layer is difficult so that at a potential region from -1.1 to $-0.5 \mathrm{~V}$ and at another potential region -0.3 to $-0.1 \mathrm{~V}$, electron transfer is blocked. In fact, the oxidation current of mercury was observed, but the reduction current of the dissolved mercury ion was not observed in Fig.4-(A). The thickness of the adsorption layer increases as the potential goes negative, and the surface tension of the

\begin{tabular}{|c|c|c|c|}
\hline \multirow{3}{*}{$\begin{array}{l}\text { Neutral } \\
\text { or } \\
\text { alkaline } \\
\text { solutions } \\
\end{array}$} & $\begin{array}{l}\text { (A) }-1.1 \mathrm{~V} \sim-0.5 \mathrm{~V} \\
\text { perpendicular } \mathrm{N}-u p\end{array}$ & $\begin{array}{c}\text { (B) }-0.5 \mathrm{~V}--0.3 \mathrm{~V} \\
\text { random }\end{array}$ & $\begin{array}{c}\text { (C) }-0.3 \mathrm{~V} \sim-0.1 \mathrm{~V} \\
\text { flat }\end{array}$ \\
\hline & 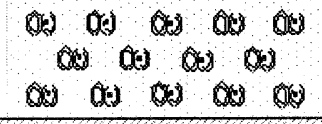 & $\infty_{-\infty}^{\infty} \infty \|_{-\infty}^{\infty} \infty$ & 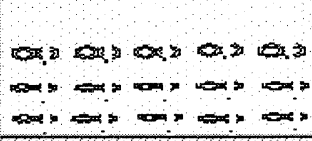 \\
\hline & \multicolumn{3}{|c|}{$\mathrm{pZc}$} \\
\hline \multirow{4}{*}{$\begin{array}{l}\text { Acidic } \\
\text { solutions }\end{array}$} & $\begin{array}{l}\text { (D) }-0.6 \mathrm{~V} \sim-0.4 \mathrm{~V} \\
\text { perpendicular } \mathrm{NH}^{+} \text {down }\end{array}$ & $\begin{array}{c}(\mathrm{E})-0.4 \mathrm{~V}-+0.2 \mathrm{~V} \\
\text { random }\end{array}$ & $\begin{array}{l}(\mathrm{F})+0.2 \mathrm{~V} \sim+0.4 \mathrm{~V} \\
\text { perpendicul ar } \mathrm{NH}^{+}-\text {up }\end{array}$ \\
\hline & 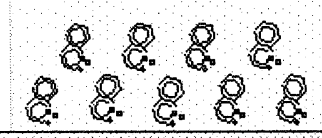 & 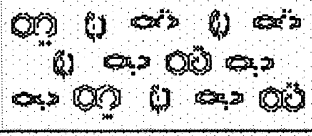 & $80 \%$ os 8 \\
\hline & 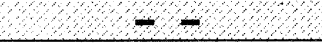 & 1 & +4 \\
\hline & negatively charged metal & $\mathrm{pzc}$ & positively charged metal \\
\hline
\end{tabular}

Fig.8 Schematic illustration of expected adsorption models of orientation of quinoline molecules and quinolinium ion near mercury electrode surface. 
interface changes. As a result, the drastic change of a dropping time of the dropping mercury electrode occurred at $-0.55 \mathrm{~V}$.

The above mentioned three kinds of orientations of quinoline molecule upon the mercury surface are consistent with the model proposed by Matsumoto et al. ${ }^{24)}$.

\subsection{Adsorption model of quinolinium ions on mercury surface}

A similar argument can be possible for the quinolinium ion existing in the acidic solution. The pzc of the mercury is $-0.41 \mathrm{~V}$, even in the presence of quinolinium ion in the acidic solution $^{16)}$. Thus the perpendicular orientation with an $\mathrm{NH}^{+}$site directed toward the negatively charged mercury surface as shown in Fig.8-(D) is consistent with electrostatic attraction when the potential is more negative than $-0.4 \mathrm{~V}$. This orientation is consistent with that proposed by Lovrecek and Cipris ${ }^{41)}$.

On the other hand, when the potential is more positive than $+0.2 \mathrm{~V}$, another perpendicular orientation with an $\mathrm{NH}^{+}$site directed toward solution (F) is favorable by hydrophobic interaction between quinoline ring and mercury surface in addition to the electrostatic repulsion and hydrophilic interaction between the charged group $-\mathrm{NH}^{+}$ and aqueous solution.

In the case of non-charged quinoline molecule existing in the alkaline solution, the flat adsorption was proposed. However, such flat adsorption is not acceptable for the quinolinium ion because the measured relative peak intensity $\mathrm{R}$ is the same or smaller than the value in the bulk solution, although the value of $\mathrm{R}$ should become much larger if the flat orientation is taken. At the potential region from -0.4 to $+0.2 \mathrm{~V}$ as shown in Fig.8-(E), random orientation is expected. When the potential of this region is applied, namely more positive than the pzc $(-0.41 \mathrm{~V})$, the mercury electrode is positively charged. Then the positively charged quinolinium ion is subjected to electrostatic repulsion. As a result, the quinolinium ions cannot take the flat orientation, but take random orientation in this potential region.

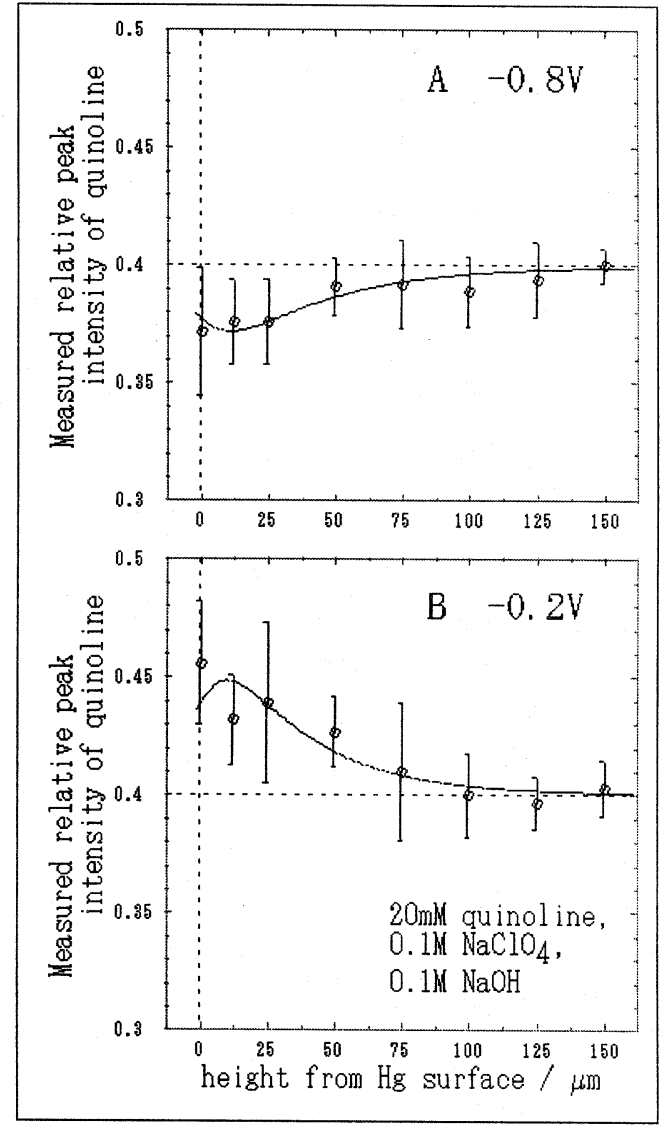

Fig.9 Dependence of relative peak intensity $\mathrm{R}$ of quinoline upon the distance from the mercury surface for $20 \mathrm{mM}$ quinoline, $0.1 \mathrm{M} \mathrm{NaClO}, 0.1 \mathrm{M}$ $\mathrm{NaOH}$ solution at (A) $-0.8 \mathrm{~V}$ and (B) $-0.2 \mathrm{~V}$. Curves shown by solid line are the results of simulation based on the reproduced profile of Fig.12.

\subsection{Relative peak intensity / distance profile of quinoline / mercury system}

In Fig.9 and Fig.10, the dependence of the relative peak intensity $R$ of quinoline upon the distance of the focal point from the mercury surface are shown. Fig.9 is that of the $20 \mathrm{mM}$ quinoline, $0.1 \mathrm{M} \mathrm{NaClO}_{4}, 0.1 \mathrm{M} \mathrm{NaOH}$ solution, and Fig.10 is that of the $40 \mathrm{mM}$ quinoline, $0.1 \mathrm{M}$ $\mathrm{HClO}_{4}$.

When $-0.8 \mathrm{~V}$ was applied in the alkaline solution, the relative peak intensity $\mathrm{R}$ increased with going up into the bulk solution as shown in Fig.9-(A). But when $-0.2 \mathrm{~V}$ was applied, it 
decreased as shown in Fig.9-(B). The $R$ values at the distance $100 \mu \mathrm{m}$ above the mercury surface were almost the same regardless with the applied potentials. The adsorption models, perpendicular orientation at $-0.8 \mathrm{~V}$ and flat orientation at $-0.2 \mathrm{~V}$, explain these results.

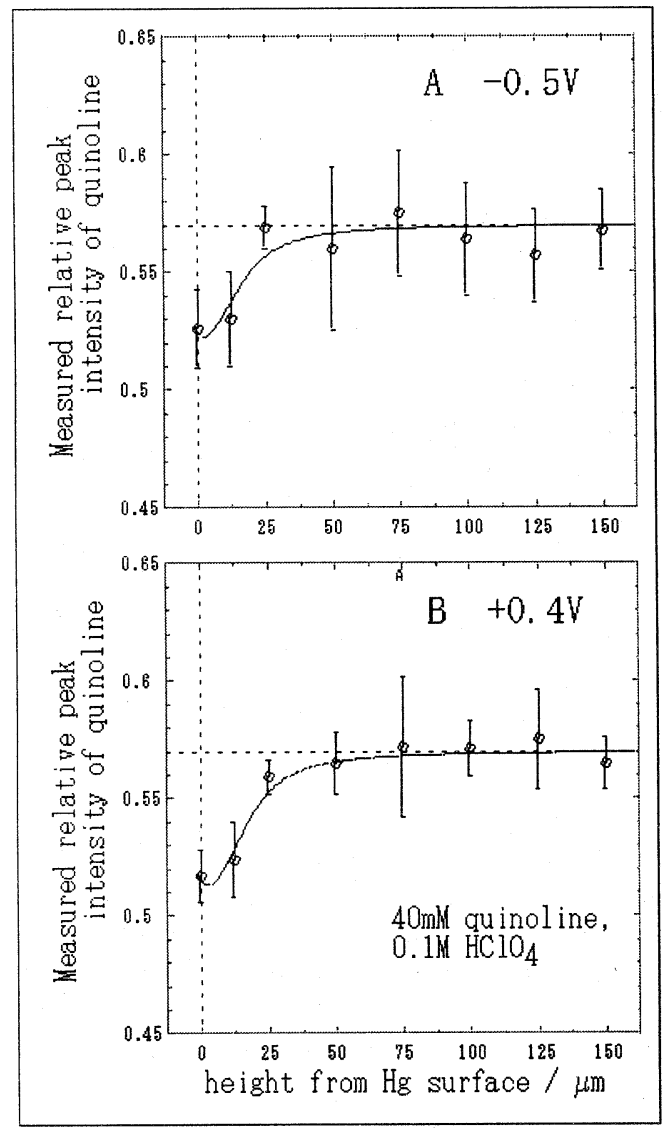

Fig.10 Dependence of relative peak intensity $\mathrm{R}$ of quinolinium ion upon the distance from the mercury surface for $40 \mathrm{mM}$ quinoline, $0.1 \mathrm{M} \mathrm{HClO}_{4}$ solution at (A) $-0.5 \mathrm{~V}$ and (B) $+0.4 \mathrm{~V}$. Curves shown by solid line are the results of simulation based on the reproduced profile of Fig.11.

On the other hand, in the acidic solution as shown in Fig.10, the relative peak intensity $R$ was decreased at the mercury surface when $-0.5 \mathrm{~V}$ or $+0.4 \mathrm{~V}$ was applied. These are explained by the model that the adsorbed quinolinium ions take perpendicular orientations upon the mercury surface at these potentials. When $0 \mathrm{~V}$ was applied, dependence of the relative peak intensity $R$ upon the distance (not shown in this report) is small because the orientation of quinolinium ion is random similar to that in the bulk solution at potential region from -0.4 to $+0.1 \mathrm{~V}$.

\subsection{Reproduced concentration / distance profile of quinoline / mercury system}

When Fig.9 and Fig.10 are compared, the distances where the relative peak intensity $R$ approaches the value of the bulk solution are different. It means that the thickness of the adsorption layer is different between in the alkaline solution and in the acidic solution. In this study, the deconvolution procedure to reproduce the true concentration / distance profile from the relative peak intensity / distance profile was carried out according to the procedure described in the section 3.3.

The reproduced concentration / distance profile are shown in Fig.11 and Fig.12. However, the vertical axes of these figures are not the concentration itself $C(h)$, rather the molar Raman scattering coefficient multiplied concentration $\mu C(h)$. The curves shown by solid line in Fig.9 and Fig.10 are the simulation results of the relative peak intensity / distance profile from the reproduced concentration / distance profiles of Fig.12 and Fig.11, respectively.

The profile of quinolinium ion in the acidic solution is shown in Fig.11. The apparent concentration $\mu C(h)$ of the quinolinium ion at the mercury surface is essentially zero in both cases (A) and (B). All the quinolinium ions existing on the electrode surface seem to take the completely ordered perpendicular orientation in the acidic solution.

On the other hand, the thickness of the adsorption layer defined by the half distance of Eq.5 is $2.78 \mu \mathrm{m}(+0.4 \mathrm{~V})$ and $2.38 \mu \mathrm{m}(-0.5 \mathrm{~V})$. These values are larger than those expected from the monolayer adsorption. There is a possibility that the surface of the mercury drop is vibrating due to thermal convection of the solution caused by the heat of laser beam. 


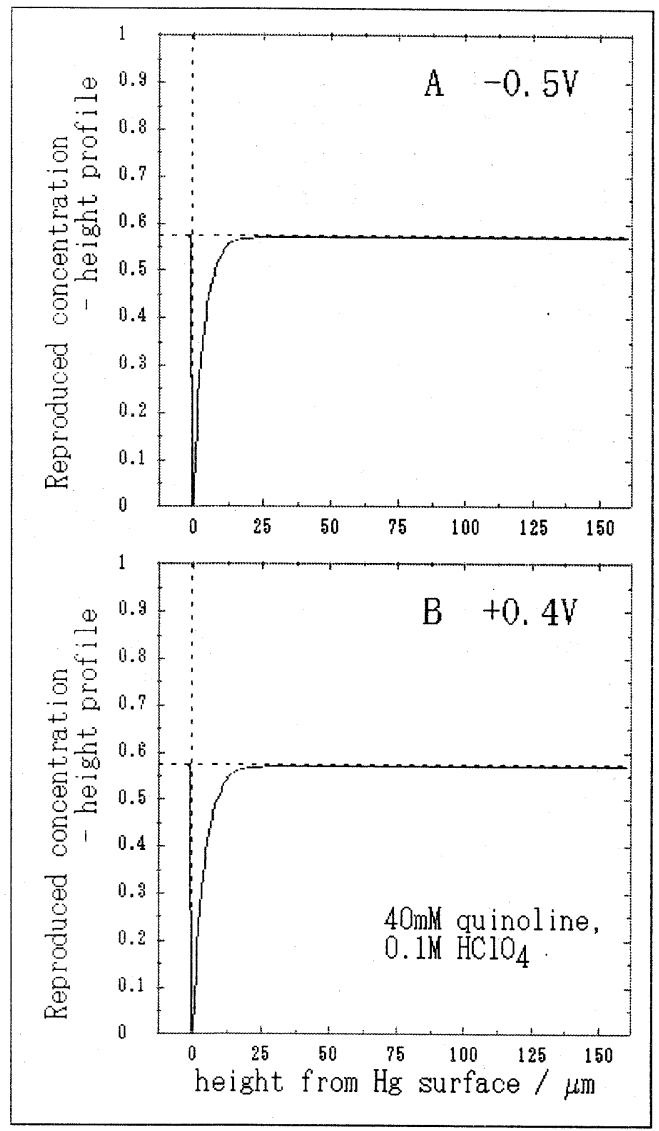

Fig.11 Reproduced concentration - distance profile of quinolinium ion from the mercury surface in the $40 \mathrm{mM}$ quinoline, $0.1 \mathrm{M} \mathrm{HClO}_{4}$ solution at (A) $-0.5 \mathrm{~V}$ and $(\mathrm{B})+0.4 \mathrm{~V}$.

In Fig.12, the reproduced concentration / distance profile of quinoline molecule in the alkaline solution is shown. When $-0.2 \mathrm{~V}$ was applied as shown in Fig.12-(B), the apparent concentration $\mu C(h)$ of quinoline molecule at the mercury surface was larger than that of the bulk. It means that quinoline molecules are taking flat orientation in the boundary region. To contrary, the apparent concentration of quinoline molecule at the mercury surface was lower than that of the bulk when $-0.8 \mathrm{~V}$ was applied as shown in Fig.12-(A). It means that quinoline molecules are taking perpendicular orientation in the boundary region, but the apparent concentration is not zero at the mercury surface although that of the quinolinium ion in the acidic solution was zero
(Fig.11). Thus, in the alkaline solution, it is suggested that a part of quinoline molecules still takes random orientation in the region although the number of molecules taking perpendicular orientation is larger than that of flat orientation.

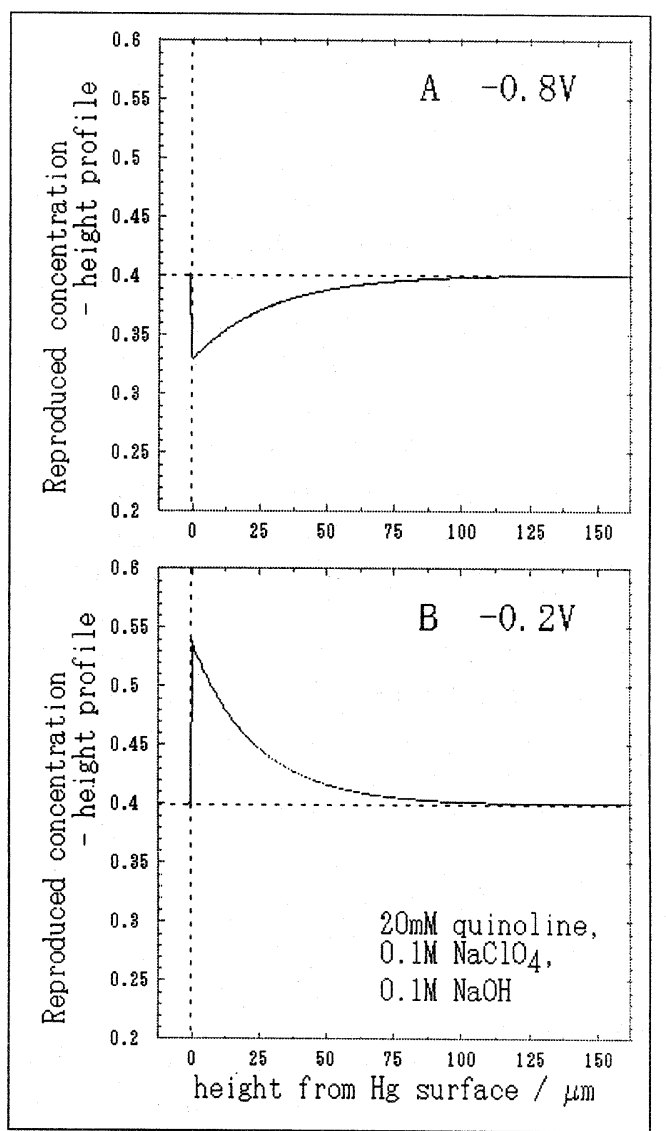

Fig.12 Reproduced concentration - distance profile of quinoline molecule from the mercury surface in the $20 \mathrm{mM}$ quinoline, $0.1 \mathrm{M} \mathrm{NaClO}_{4}$, $0.1 \mathrm{M} \mathrm{NaOH}$ solution at $(\mathrm{A})-0.8 \mathrm{~V}$ and $(\mathrm{B})-0.2 \mathrm{~V}$.

On the other hand, the thickness defined as the half distance (Eq.5) is $16.30 \mu \mathrm{m}$ when $-0.2 \mathrm{~V}$ is applied, and $20.41 \mu \mathrm{m}$ when $-0.8 \mathrm{~V}$ is applied. These values are obviously larger than those obtained for the quinolinium ion existing in the acidic solution. It means that the thickness of the adsorption layer of quinoline molecules in the alkaline solution is larger than that of the quinolinium ions in the acidic solution. Namely, the adsorption of quinoline molecule is 
not monolayer, rather a multi-layer condensation of quinoline molecules occurs. This result seems to be consistent with the fact that the condensation of oily substance onto the mercury surface was observed by the microprobe when much more negative potential is applied.

\section{CONCLUSION}

The intensity / distance profile Raman microprobe spectroscopy was developed. By applying deconvolution treatment, the real concentration / distance profile in the metal / solution boundary region was obtained. Furthermore the direction of orientation of the species was estimated with the precision of several $\mu \mathrm{m}$ based on the interaction model of laser beam and orientation of the molecule.

In this report, the technique was applied to the adsorption of quinoline molecule existing in an alkaline solution and that of quinolinium ion existing in an acidic solution onto the mercury electrode. Adsorption of quinolinium ion and condensation of quinoline molecule were observed, and their orientations depended upon the applied potential.

In recent years, the confocal Raman spectroscopy has been developed. The focal depth of the confocal system is much narrower than that used here. But the concept of convolution and deconvolution as to the intensity / distance profile is still useful to improve spatial resolving power of the measurement.

\section{REFERENCES}

1) Y. Fukunaka, T. Minegishi, N. Nishioka, Y. Kondo, J. Electrochem. Soc., 128, 1274 (1981).

2) J. Matysik, J. Chmiel, A. Cieszczyk -Chmiel, J. Electroanal. Chem., 195, 39 (1985).

3) C. -C. Jan, R. L. McCreery, Anal. Chem., 58, 2771 (1986).

4) R. L. McCreery, Progr. Anal. Spectrosc., 11, 141 (1988).

5) J. Pawliszyn, Anal. Chem., 60, 1751
(1988).

6) J. Pawliszyn, M. F. Weber, M. J. Dignam, A. Mandelis, R. D. Venter, S. -M. Park, Anal. Chem., 58, 239 (1986).

7) J. L. Lipkowski, P.N. Ross, (Eds.), Adsorption of Molecules at Metal Electrodes, VCH Publishers, New York, (1992).

8) J. L. Lipkowski, P.N. Ross, (Eds.), Structure of Electrified Interfaces, VCH Publishers, New York, (1993).

9) J. L. Lipkowski, P.N. Ross, (Eds.), Imaging of Surfaces and Interfaces, Wiley-VCH, New York, 1999.

10) A.Iannelli, A.G.Brolo, D.E.Irish, J.Lipkowski, Can.J.Chem. 75, 1694 (1997).

11) B. D. Smith, D. E.Irish, P. Kedzierzawki, J. Augustynski, J. Electrochem. Soc., 144, 4288 (1997).

12) T. Ozeki, D. E. Irish, J. Electroanal. Chem., 280, 451 (1990).

13) T. Ozeki, D. E. Irish, Bunseki Kagaku, 40, 791 (1991).

14) T. Ozeki, D. E. Irish, J. Phys. Chem., 96, 1306 (1992).

15) T. Ozeki, M. Odziemkowski, D.E.Irish, J.Solution Chem., 29, 861 (2000).

16) T.Ozeki, K. Yokoi, M.Odziemkowski, D.E.Irish, J.Electroanal.Chem., 505, 142 (2001).

17) G. Jones (Ed.) Quinolines (Part1), The Chemistry of heterocyclic compounds; vol.32, Wiley, London, pp.20-22 (1977).

18) T. Ozeki, D. Irish, J. Phys. Chem., 96, 1302 (1992).

19) A.F.Carley, R.W.Joyner, J. Electron Spectrosc. Relat. Phenom., 16, 1 (1979).

20) P.A. Jansson, (Ed.), deconvolution with Applications in Spectroscopy, Academic Press, Orlando, FL, (1984).

21) T. Ozeki, I. Watanabe, S. Ikeda, J.Electroanal. Chem., 152, 41 (1983).

22) D. L. Massart, B. G. M. Vandeginste, S. N. Deming, Y. Michotte, L. Kaufman, Data Handling in Science and Technology Vol.2, Chemometrics: A Textbook, Elsevier, Amsterdam, p.301 (1988).

23) H. Sawamoto, J. Electroanal. Chem., 432, 153 (1997). 
24) F. Matsumoto, K. Tokuda, T. Ohsaka, J. Deuterium Sci., 5, 23 (1996).

25) M. W. Hamphereys, R. Parsons, J. Electroanal. Chem., 82, 369 (1977).

26) Cl. Buess-Herman, L. Gierst, N. Vanlaethem - Meuree, J. Electroanal. Chem., 123, 1 (1981).

27) Cl. Buess- Herman, N. VanlaethemMeuree, G. Quarin, L. Gierst, J. Electroanal. Chem., 123, 21 (1981).

28) G. Quarin, Cl. Buess- Herman, L. Gierst, J. Electroanal. Chem., 123, 35 (1981).

29) D. J. Blackwood, S. Pons, J. Electroanal. Chem., 247, 277 (1988).

30) T. Fujinaga, K. Izutsu, K. Takaoka, J. Electroanal. Chem., 12, 203 (1966).

31) J. Claret, C. Muller, J. M. Feliu, J. Virgili, Electrochimica Acta, 27, 1475 (1982).

32) D. N. Schluter, T. Biegler, E. V. Brown, H. H. Bauer, J.Electroanal.Chem., 75, 545 (1977).
33) J. T. Folliard, R. E. Cover, J. Electroanal. Chem., 33, 463 (1971).

34) F. Matsumoto, K. Tokuda, T. Ohsaka, Electroanalysis, 8, 648 (1996).

35) J. Lipkowski, L. Stolberg, S. Morin, D. E. Irish, P. Zelenary, M. Gamboa, W. Wieckowski, J. Electroanal. Chem., 355, 147 (1993).

36) Z. Deng, D. E. Irish, J. Phys. Chem., 98, 11169 (1994).

37) A. G. Brolo, D. E. Irish, B. D. Smith, J. Molecular Structure, 405, 29 (1997).

38) S. C. Wait, Jr., J. C. McNerney, J. Mol. Spectrosc., 34, 56 (1970).

39) E. R. Lippincott, E. J. O'Reilly,Jr., J. Chem. Phys., 23, 238 (1955).

40) MOPAC Version 7.0 for Power Macintosh.

41) B. Lovrecek, D. Cipris, J. Electroanal. Chem., 11, 44 (1996). 